\title{
Effect of secretory immunoglobulin A on bacterial translocation in an enterocyte-lymphocyte co-culture model
}

\begin{abstract}
Intestinal secretory immunoglobulin A (sIgA) plays an important role in gut mucosal immunity in vivo; however, in-vitro enterocyte models for studying the mechanisms of these effects are lacking. This study utilizes a cell-culture model to investigate the effect of $\operatorname{sIgA}$ on bacterial translocation (BT) across human enterocytes co-cultured with human lymphoid cells (Raji cells). This model is intended to mimic in-vivo enterocyte/lymphocyte interactions found in intestinal follicle-associated epithelia. Human Caco-2 enterocytes were grown to confluence on porous filters in the apical chamber of a two-chamber cell-culture system. After differentiation, human B lymphoid cells (Raji cells) were added to the basolateral surface of Caco-2 monolayers for 3 days' coculture, followed by washing away of unincorporated Raji cells. Transepithelial electrical resistance (TEER) was used to measure tight-junction permeability. Monolayers were treated with or without $\operatorname{sgA}, \operatorname{IgG}$ (negative control), or mannose (positive control). BT across the cell monolayer was determined $1.5 \mathrm{~h}$ after addition of Escherichia coli. Statistical analysis was by the KruskalWallis test, $P$ below 0.05 considered significant. In coculture monolayers treated with $\operatorname{sgA}, \operatorname{IgG}$, or mannose, there was no significant effect on TEER; however, the magnitude of BT across cells treated with $\operatorname{sIgA}(1.3 \pm 0.4$ $\left.\log _{10} \mathrm{CFU} / \mathrm{ml}\right)$ and mannose $\left(1.6 \pm 1.1 \log _{10} \mathrm{CFU} / \mathrm{ml}\right)$ was significantly decreased compared to PBS $(3.9 \pm 0.4$ $\left.\log _{10} \mathrm{CFU} / \mathrm{ml}\right)$ and $\operatorname{IgG}\left(2.9 \pm 0.6 \log _{10} \mathrm{CFU} / \mathrm{ml}\right)$ controls $(P<0.05)$. sIgA BT inhibition was dose-dependent. BT inhibition by SIgA and mannose was additive $\left(0.5 \pm 1 \log _{10} \mathrm{CFU} / \mathrm{ml}\right)$. Inhibition of BT was negated when SIgA and mannose were removed by washing prior to $E$. Coli addition $\left(3.6 \pm 0.5 \log _{10} \mathrm{CFU} / \mathrm{ml}\right)$, suggesting that both inhibitors act through bacterial binding.
\end{abstract}

T. Sawai $\cdot$ N. Goldstone $\cdot$ R. A. Drongowski

A. G. Coran · C. M. Harmon $(\bowtie)$

Section of Pediatric Surgery,

University of Michigan,

Mott Children's Hospital, Ann Arbor,

MI 48109-0245, USA
Keywords Bacterial translocation - Enterocytes ·

Secretory immunoglobulin A

\section{Introduction}

The intestinal mucosa not only absorbs ingested nutrients, but also functions as the largest lymphoepithelial organ, participating as an important component of the gut barrier to luminal bacteria [10]. Bacterial translocation (BT) across the intestinal mucosa may be a source of infection in neonates, and this phenomenon may be caused in part by the immaturity of the neonatal gut-mucosal barrier. The gut-associated lymphoid tissue (GALT) synthesizes more immunoglobulins (Ig) than any other lymphoid organ, and therefore, may play an integral role in regulating BT across the intestine [8]. Recent studies have shown that secretory Iga (sIgA), the principal Ig produced by GALT, may play a role in the prevention of BT [11].

We have previously reported that neonatal rabbits have a higher incidence of spontaneous BT that adult rabbits [13]. However, the cause of this increased incidence of BT remains unclear. sIgA is virtually nonexistent in newborns, who do not produce their own sIgA at a significant level until at least the 2 nd week of life [3]. The predominant Ig found in breast milk is $\operatorname{IgA}$, and previous studies have demonstrated that neonatal rabbits fed breast milk show a greatly reduced occurrence of BT [3]. It has also been reported that sIgA reduces BT across the rat ileum using an Ussing chamber system [1]. However, in-vivo models designed to study this event have limitations.

An in-vitro Madin-Darby canine kidney (MDCK) cell-culture model has been used to study the effect of sIgA on inhibition of BT and adherence to epithelium $[4,12]$. These studies have suggested that the MDCK cell-culture model is useful for investigating the role of SIgA in intestinal barrier function. However, MDCK epithelial cells are kidney, not intestinal epithelial cells. Recently, a report using a human colonic carcinoma 
(Caco-2) monolayer and sIgA to study an interaction between Escherichia coli and Candida albicans [5] demonstrated that sIgA inhibited BT across Caco- 2 monolayers. In addition, Caco-2 cell monolayers have been used to demonstrate that E. coli $\mathrm{BT}$ could be reduced by the addition of mannose to the apical side of the epithelial cells [2].

Recently, an in-vitro model has been described to study the transcytosis of micro-organisms and antigens across intestinal epithelia co-cultured with lymphocytes isolated from Peyer's patches [8]. This model makes it possible to analyze specific properties of the enteryocyte/ lymphocyte interaction that may occur in the gut. We have previously modified this model using human Caco2 enterocytes co-cultured with human B lymphoid (Raji) cells to study BT under a variety of conditions [15].

Our aim in this study was to investigate the mechanisms by which sIgA and mannose might prevent BT across intestinal mucosa using a unique in-vitro enterocyte/lymphoid-cell co-culture monolayer model and secretory $\operatorname{IgA}$ from human colostrum.

\section{Materials and methods}

Caco-2 cells were obtained from the American Type Culture Collection No. HTB 37 (Manassas, VA). E. coli $C-25$ was provided by Dr. Henri R. Ford (Pittsburgh, PA). Dulbecco's modified Eagle's medium (DMEM), fetal bovine serum (FBS), non-essential amino acid (NEAA) solution, sodium pyruvate, penicillin G, streptomycin, and trypsin-EDTA were obtained from Gibco (Grand Island, NY). A two-chamber cell-culture system and MacConkey's agar were purchased from Fischer (Pittsburgh, PA). Rat-tail type I collagen, sIgA, and D-mannose were purchased from Sigma (St Louis, MO). Brain-heart infusion medium was obtained from Baltimore Biological Laboratories (Cockeysville, MD).

Caco-2 cells are transformed human colon carcinoma cells that spontaneously form polarized monolayers and tight junctions. Cells were cultured in DMEM supplemented with $10 \%$ FBS $1 \%$ NEAA, 0.01 M HEPES buffer, and antibiotics (100 IU $/ \mathrm{ml}$ penicillin $\mathrm{G}, 100 \mu \mathrm{g} / \mathrm{ml}$ streptomycin) at $37^{\circ} \mathrm{C}$ in a humidified atmosphere of $5 \% \mathrm{CO}_{2}$ in air. Once cells reached $70 \%$ confluence, they were harvested by trypsinization $(0.25 \%$ trypsin and $0.53 \mathrm{mM}$ EDTA), washed, and resuspended in DMEM.

Raji cells, lymphoid cells with features similar to B cells, are derived from human Burkitt lymphoma cells. These cells were grown in RPMI 1640 supplemented with $10 \%$ FBS, with media changes every other day. Specified cell suspensions were made with supplemented DMEM media.

Before seeding of Caco-2 cells, $30 \mu \mathrm{l}$ collagen solution $(1.0 \mathrm{mg} / \mathrm{ml}, 80 \%$ ethanol; rat-tail type 1$)$ was applied to the apical chamber porous platform and the transwells were dried overnight. The Caco-2 cells were seeded on the apical side of a transwell $(3.0 \mu \mathrm{m}$ pore-size membrane) bicameral chamber (Costar, Cambridge, MA), grown for 14 days, and allowed to form polarized cell monolayers. Media were changed every other day. Monolayer formation was monitored by measuring transepithelial electrical resistance (TEER) with a Millicell electrical resistance system (Millipore EVOM-6; World Precision Instruments). Caco2 cells were used after a TEER of $130 \Omega / \mathrm{cm}^{2}$ had been achieved, indicating monolayer integrity. After the cells were fully differentiated, the apical chambers were inverted in the culture media and Raji cells were added to the lower surface of the membrane. After 3 days of co-culture, unincorporated Raji cells were removed by washing and the apical chambers were placed upright in the basal chambers. These monolayers were provided as co-culture models.
The bacterial probe used in this study was $E$. coli $C 25$, a nonpathogenic, streptomycin-resistant strain originally isolated from human gut flora. E. coli are members of the Enterobacteriaceae, and gram-negative enteric bacteria are among the most common organisms recovered in animal experiments or from the blood of immunocompromised patients with primary bacteremia. E. coli were grown overnight in brain-heart infusion medium, washed two times with phosphate buffered saline (PBS), and resuspended in DMEM. A concentration of $2 \times 10^{7} / \mathrm{ml}$ was used in the co-culture, while a concentration of $1 \times 10^{8} / \mathrm{ml}$ was used in the gentamicin killing assay (GKA).

The following three experiments were performed to investigate the mechanism of sIgA: (1) SIgA $(100 \mu \mathrm{g} / \mathrm{ml})$, D-mannose $(12 \mathrm{mg} /$ $\mathrm{ml})$, and $\operatorname{IgG}(100 \mu \mathrm{g} / \mathrm{ml})$ diluted to the specified concentrations with PBS were added to the apical chamber. The transwells were incubated for $30 \mathrm{~min}$ to stabilize the treating solution, followed by the addition of E. coli $C 25$ to the apical chamber. After 90 min incubation, samples of media $(100 \mu \mathrm{l})$ were removed from the basal compartments and spread on MacConkey agar plates for quantitative colony-forming unit (CFU) analysis. In order to verify monolayer integrity, TEER was measured at the beginning and end of the experiment with alcohol-sterilized electrodes. (2) SIgA $(100 \mu \mathrm{g} / \mathrm{ml})$, D-mannose $(12 \mathrm{mg} / \mathrm{ml})$, and or $\mathrm{IgG}(100 \mu \mathrm{g} / \mathrm{ml})$ was added to the apical chambers and allowed to incubate for $30 \mathrm{~min}$. The surfaces of the apical sides were then washed with PBS to remove the unbound epithelial sIgA and/or mannose. E. coli $C 25$ was added to the apical chambers, followed by BT and TEER determination using the methods described above. (3) SIgA and/or mannose was incubated for $1.5 \mathrm{~h}$ with $E$. coli, followed by centrifugation and washing with PBS three times to remove unbound sIgA and/or mannose. These E. coli were then applied to the apical chambers, followed by BT and TEER determination with the methods described above.

In order to determine whether inhibition of BT was due to inability of the $E$. coli to bind and internalize, we conducted experiments using the GKA $[9,16]$. The Caco-2 monolayer, which was confluent on 24-well plates, was treated with varying concentrations of sIgA, D-mannose, or a combination of both. Cells were incubated with $E$. coli $C 25$ for 90 min. The monolayers were washed six times with PBS followed by the addition of DMEM containing $100 \mu \mathrm{g} / \mathrm{ml}$ gentamicin in order to kill any remaining viable extracellular bacteria. It is reported that $E$. coli can survive within Caco-2 cells [17] and that gentamicin $(100 \mu \mathrm{g} / \mathrm{ml})$ is not transported by Caco-2 cells, and thus should not affect the viability of intracellular bacteria [14]. After $2 \mathrm{~h}$, the monolayers were washed six times with PBS and lysed with $0.5 \%$ Triton X-100. These cell lysates were then diluted and spread on MacConkey agar plates for quantitative CFU analysis. The magnitude of bacterial internalization (BI) was quantitatively measured by counting bacterial colonies after pour-plate assay.

The BT and BI data were $\log 10$-transformed prior to analysis. An unpaired two-tailed $t$-test was used to compare the magnitude of BT between treated Caco-2 monolayers and controls. Significance was achieved with $P$ values of 0.05 or less. All data are expressed as mean \pm standard deviation.

\section{Results}

\section{Effect of $\operatorname{sIgA}$ or mannose on TEER}

As previously described, the co-culture of Caco-2 cells with human lymphoid cells resulted in decreasing TEER. SIgA, IgG, and/or mannose had no significant effect on TEER under co-culture conditions (Fig. 1). When sIgA and mannose were removed by washing prior to E. coli addition, there was also no significant effect on TEER. Moreover, the addition of $E$. coli pre-incubated with sIgA and/or mannose to the apical surface of the monolayer had no significant effect on TEER. 
Fig. 1 Effects of IgA, mannose (man), and IgG on transepithelial electrical resistance (TEER) across Caco-2 monolayers cocultured with Raji cells. TEER was measured before and $2 \mathrm{~h}$ after addition of substances.

Data expressed a mean $\pm \mathrm{SD}$ (PBS phosphate-buffered saline)
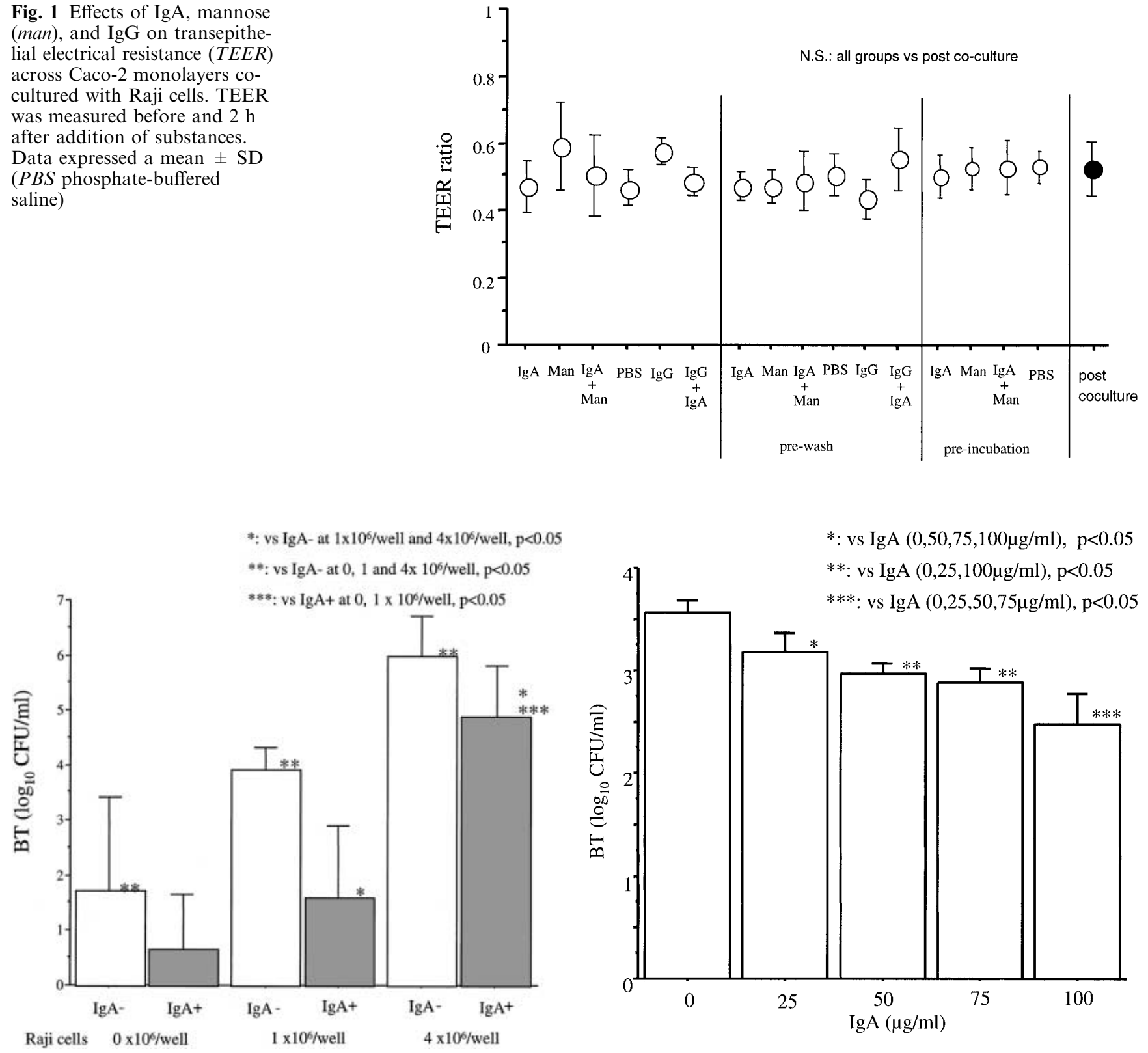

Fig. 2 Effects of $\operatorname{IgA}$ on bacterial translocation $(B T)$ (expressed as $\left.\log _{10}[\mathrm{CFU} / \mathrm{ml}]\right)$ across Caco-2 monolayers co-cultured with $0,1 \times 10^{6}$, and $4 \times 10^{6}$ Raji cells. BT was measured $1.5 \mathrm{~h}$ after addition of IgA $(100 \mu \mathrm{g} / \mathrm{ml})$. Data expressed as mean $\pm \mathrm{SD} .{ }^{*} P<0.05 \mathrm{vs} \operatorname{IgA}+$ at $1 \times 10^{6} /$ well, and $4 \times 10^{6} /$ well; $* * P<0.05$ vs IgA- at $0,1 \times 10^{6} /$ well, and $4 \times 10^{6} /$ well; $* * * P>0.05$ vs $\operatorname{IgA}+$ at 0 and $1 \times 10^{6} /$ well

\section{Effect on BT}

Based upon previous work in our laboratory, BT increases in a dose-dependent manner in relation to the number of lymphoid cells added to the co-culture system. Similary, in this study sIgA significantly inhibited BT under co-culture conditions when compared to cultures with no sIgA treatment (Fig. 2). SIgA also inhibited BI in the GKA in a dose-dependent manner (Fig. 3).

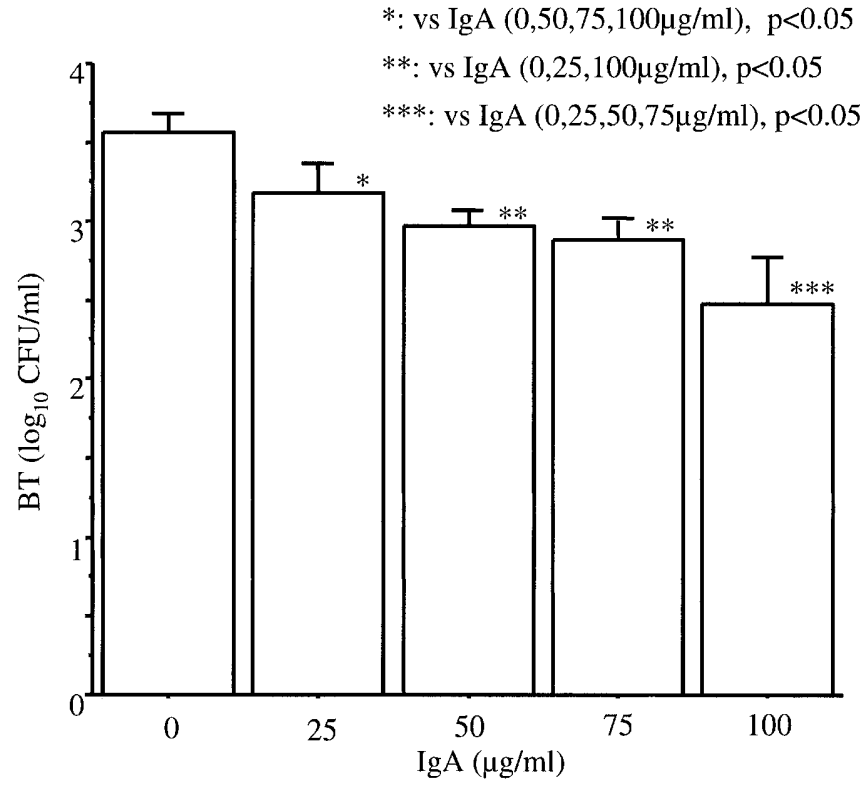

Fig. 3 Internalization (expressed as $\log _{10}[\mathrm{CFU} / \mathrm{ml}]$ ) of $E$. coli in Caco-2 monolayers treated with $\operatorname{IgA} 1.5 \mathrm{~h}$ after addition of $\operatorname{IgA}(0,25,50$, $75,100 \mu \mathrm{g} / \mathrm{ml})$. Data expressed as mean $\pm \mathrm{SD}$ (BT bacterial translocation). $* P<0.05$ vs $\operatorname{IgA}(0, \quad 50, \quad 75,100 \mu \mathrm{g} / \mathrm{ml}) ; * * P$ $<0.05$ vs $\operatorname{IgA}(0,25,100 \mu \mathrm{g} / \mathrm{ml}) ; * * * P>0.05$ vs $\operatorname{IgA}(0,25,50$, $75 \mu \mathrm{g} / \mathrm{ml})$

The magnitude of BT across cells treated with sIgA and/or mannose was significantly decreased compared to PBS and IgG as controls under co-culture conditions (Fig. 4). BT inhibition by the combination of sIgA and mannose was additive. Inhibition of BT was negated when sIgA and mannose were removed from the apical chamber by washing prior to $E$. coli addition, suggesting that both inhibitors act through bacterial binding (Fig. 5). The addition of the E. coli pre-incubated with sIgA and/or mannose decreased BT compared to PBS as a control (Fig. 6). 


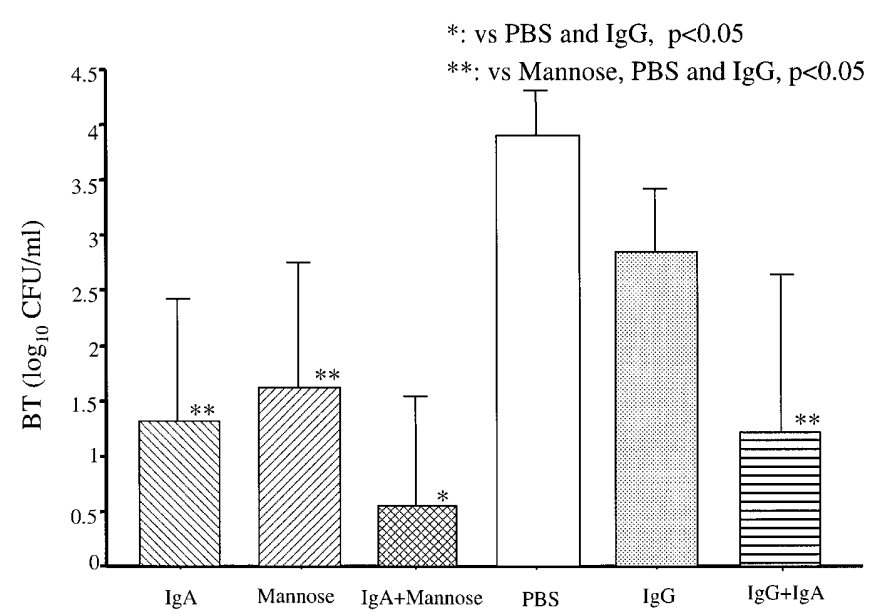

Fig. 4 Effect of sIgA, mannose and IgG on bacterial translocation (BT) across Caco-2 monolayers co-cultured with Raji cells $1 \times 10^{6} \%$ well. BT was measured $1.5 \mathrm{~h}$ after addition of $\operatorname{sigA}(100 \mu \mathrm{g} / \mathrm{ml})$, mannose $(12 \mathrm{mg} / \mathrm{ml})$, and $\mathrm{IgG}(100 \mu \mathrm{g} / \mathrm{ml})$. Data expressed as mean $\pm \mathrm{SD} . * P<0.05$ vs PBS and $\mathrm{IgG} ;{ }^{* *} P<0.05$ vs mannose, $\mathrm{PBS}$, and $\operatorname{IgG}$

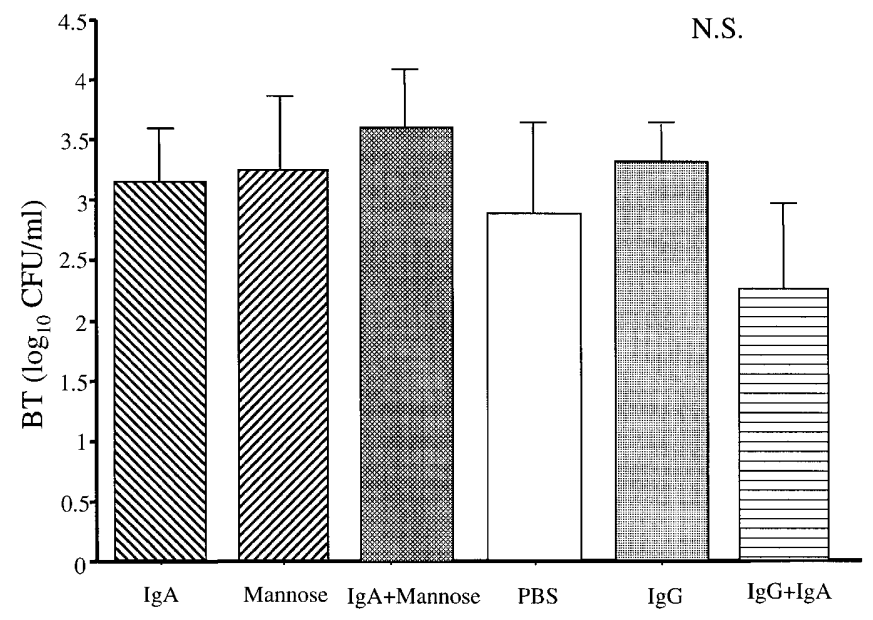

Fig. 5 Bacterial translocation (BT) across Caco-2 monolayers cocultured with Raji cells $1 \times 10^{6}$ well after removing IgA, mannose, or $\mathrm{IgG} 1.5 \mathrm{~h}$ after removal of $\mathrm{IgA}(100 \mu \mathrm{g} / \mathrm{ml})$, mannose $(100 \mathrm{mg} / \mathrm{ml})$, and $\operatorname{IgG}(12 \mu \mathrm{g} / \mathrm{ml})$. Data expressed as mean $\pm \mathrm{SD}$

\section{Discussion}

A unique in-vitro enterocyte/lymphoid-cell co-culture monolayer model was used in our study. In this model, "M cells" are formed in the monolayer after co-culture with lymphoid cells [8]. M cells are an unusual type of epithelial cell without surface microvilli or glycocalyx. They have very prolonged cytoplasm with extensions into the lamina propria, forming a pocket. $\mathrm{M}$ cells also overlie the only true organized lymphoid structures in the gut-associated lymphoid tissue, Peyer's patches [11]. $M$ cells have been shown to sample antigens from the gut lumen, especially large particulate antigens and a number of bacteria and viruses for which they express receptors (lectin-like molecules) [7]. Antigens pass

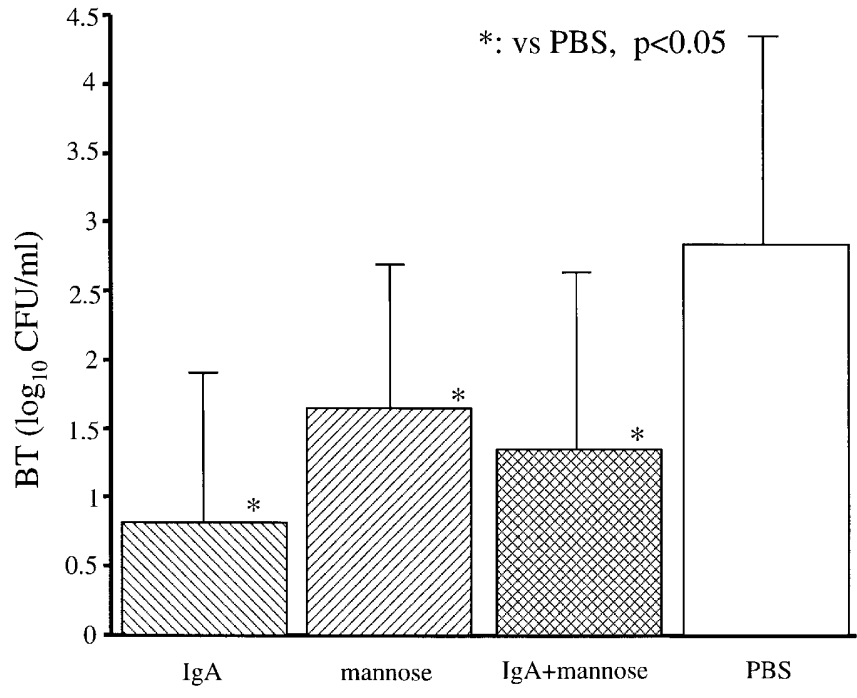

Fig. 6 Bacterial translocation $(B T)$ across Caco-2 monolayer using E. coli pre-incubated with IgA and/or mannose, co-cultured with Raji cells $1 \times 10^{6} /$ well. BT measured $1.5 \mathrm{~h}$ after addition of $E$. coli preincubated with $\operatorname{IgA}(100 \mu \mathrm{g} / \mathrm{ml})$, mannose $(12 \mathrm{mg} / \mathrm{ml})$, and $\operatorname{IgG}$ $(100 \mu \mathrm{g} / \mathrm{ml})$ for $1.5 \mathrm{~h}$. Data expressed as mean \pm SD ( $P B S$ phosphate-buffered saline). ${ }^{*} P<0.05$ vs PBS

through the $\mathrm{M}$ cells intact and are taken up by macrophages in the M-cell pocket [6]. Therefore, the formation of $\mathrm{M}$ cells in this co-culture model causes increased BT. The epithelium that lines the gut is impermeable to macromolecules and micro-organisms except in Peyer's patches, where the lymphoid follicle-associated epitheilium (FAE) contains $M$ cells that transport antigens and micro-organisms.

Our study demonstrated that the exofacial addition of sIgA from colostrum onto our enterocyte co-culture cell monolayer containing $\mathrm{M}$ cells inhibited $\mathrm{BT}$ without affecting TEER, a measure of tight-junction permeability. Moreover, through this series of experiments, including the GKA, we have shown that sIgA inhibits BI into an enterocyte cell. Furthermore, sIgA had no effect on BT when sIgA was removed from the apical surface prior to the address of E. coli, and E. coli pre-incubated with sIgA produced less BT across the Caco-2 monolayers. This suggests that $\operatorname{IgA}$ binds directly to E. coli, thus preventing its adherence to the surface of the epithelium. It has also been reported that mannose inhibits BT [2]. According to our results, mannose also binds $E$. coli. The mechanism by which mannose inhibits BT is likely the same as for sIgA.

An in-vitro MDCK cell-culture model has been previously used to study the effects of secretory $\operatorname{IgA}$ on BT $[4,12]$. However, MDCK epithelial cells are kidney, not intestinal epithelial cells. There was one other report using Caco-2 monolayers and sIgA to study interactions between E. coli and C. albicans [5]. However, Caco-2 monolayers are only epithelium except for the lymphoid FAE that contains $M$ cells. A culture model that reproduces the main characteristics of FAE and M cells is necessary to study the immunology of intestinal inter- 
actions with sIgA. This model could be useful for studying intestinal physiology, including mucosal defense systems.

\section{References}

1. Albanese C, Smith S, Watkins S, Kurkchubasche A, Simmons R, Rowe M (1994) Effect of secretory IgA on transepithelial passage of bacteria across the intact ileum in vitro. J Am Coll Surg 179: 679-688

2. Cruz N, Alvarez X (1994) Role of mucin, mannose, and beta-1 integrin receptors in Escherichia coli translocation across Caco2 cell monolayers. Shock 2: 121-126

3. Dickinson EC, Gorga JC (1998) Immunogloblin A supplementation abrogates bacterial translocation and preserves the architecture of the intestinal epithelium. Surgery 124: 184-290

4. Diebel L, Liberati D, Dulchavsky S, Myers T, Diglio C, Painter T, Brown W (1997) An in vitro model to assess mucosal immune function and bacterial translocation. J Surg Res 69: 178-182

5. Diebel LN, Liberati DM, Digliob CA, Dulchavsky SA, Brown WJ (1999) Synergic effects of Candida and Escherichia coli on gut barrier function. Trauma Injur Infection Crit Care 47: $1045-1051$

6. Emark TH, Steger HJ, Pappo J (1990) Phenotypically distinct subpopulations of $\mathrm{T}$ cells in domes and M-cell pockets of rabbit gut-associated lymphoid tissue. Immunology 71: 530-537

7. Giannasca PJ, Giannasca KT, Falk P, Gordon JI, Neutra MR (1994) Regional differences in glucoconjugates of intestinal M cells in mice: potential targets for mucosal vaccines. Am J Physiol 267: G1108-G1121
8. Kerneis S, Bogdanova A (1997) Coversion by Peyer's patch lymphocytes of human enterocytes into $M$ cells that transport bacteria. Science 277: 949-952

9. Kops SK, Lower DK, Bement WM, West AB (1996) Migration of Salmonella typhi through intestinal epithelial monolayers: an in vitro study Microbiol Immunol 40: 799-811

10. Lawrence DN, David LM (1999) Secretory immunoglobulin A blocks hypoxia augmented bacterial passage across MadinDarby canine kidney cell monolayers. Trauma 43: 759-763

11. Mayer L (2000) Mucosal immunity and gastrointestinal antigen processing. J Pediatr Gastroenterol Nutri 30: S4-S12

12. Michetti P, Porta N, Mahan MJ, Slauch JM, Mekalanos JJ, Blum AL, Kraehenbuhl JP, Neutra MR (1994) Monoclonal immunoglobulin A prevents adherence and invasion of polarized epithelial cell monolayers by Salmonella typhimurium Gastroenterology 107: 915-923

13. Okuyama H, Urao M, Lee D, Drongowski R, Coran A (1998) The effect of epidermal growth factor on bacterial translocation in newborn rabbits. J Pediatr Surg 33: 225-228

14. Ranaldi G, Islam K, Sumbuy Y (1992) Epithelial cells in culture as a model for the intestinal transport of antimicrobial agents. Antimicrob Agents Chemother 36: 1374-1381

15. Usui N, Coran A (1998) Effects of lymphoid cells on bacterial translocation, epithelial resistance, and permeability in an enterocyte cell culture model. Surg Forum 49: 573-575

16. Wells CL, Jechorek RP, Erlandsen SL (1995) Inhibitory effect of bile on bacterial invasion of enterocytes: possible mechanism for increased translocation associated with obstructive jaundice. Crit Care Med 23: 301-307

17. Wells CL, van de Westerlo EMA, Jechorek RP, Erlandsen SL (1996) Intracellular survival of enteric bacteria in cultured human enterocytes. Shock 6: 27-34 